\title{
EFFECT OF FABRIC WEAVE ON STICK-SLIP PROPERTIES OF WOVEN FABRICS
}

\author{
Kadir Bilisik
}

Erciyes University, Engineering Faculty, Department of Textile Engineering, 38039 Talas-Kayseri, Turkey

Tel:+03524378737; Fax:+03524375784, Email: kadirbilisik@gmail.com

\begin{abstract}
:
The aim of this study was to understand the stick-slip properties of dry polyester plain, ribs and satin woven fabric weaves. It was found that the amount of stick-slip force was related to the number of interlacement points in the fabric, whereas the amount of accumulative retraction force was related to fabric structural response. Stick-slip force and accumulative retraction force depend on fabric weave, fabric density, the number of pulled ends in the fabric and fabric sample dimensions. The weft directional single and multiple yarn stick-slip and accumulative retraction forces of dry plain fabrics in fabric edge and centre regions were higher than those in the satin fabric due to fabric weave. In addition, the warp directional single and multiple yarn stick-slip and accumulative retraction forces in the meso-cell-1 to the meso-cell-6 of dry wide and long satin fabric in fabric edge were higher than those in the weft direction due to fabric density. Stick-slip and accumulative retraction forces of polyester fabric in the multiple yarn pull-out test were higher than those of the single yarn pull-out test.
\end{abstract}

\section{Keywords:}

Fabric weaves, single and multiple yarn pull-outs, stick-slip force, accumulative retraction force, pull-out fixture.

\section{Introduction}

A study revealed that inter-filament friction on certain deformation characteristics of weaves was important, and that interfacial friction directly influenced yarn stiffness and weave stiffness. External yarn-to-yarn contact on adjacent yarns also directly influenced the forces required to remove yarns from fabric. These forces were in part governed by the compliance of the weave, which was a function of the friction characteristics of the filaments in the yarn. Modifying the frictional characteristics to the smallest scale in a weave structure thus directly changed the behaviour of the weave on progressively larger structural scales [1-5]. Another study was carried out on the factors involved when a single yarn was progressively pulled from the weave. As the pull-out force increased, the fabric distorted and the pull-out yarn extended at a critical force and the cross-over junctions ruptured. After a short phase of intermittent motion, the rest of the pull-out proceeded in a smoother manner and the pull-out force steadily decreased in proportion to the number of remaining cross-over contacts [6]. The softening treatment of fabric was shown to reduce inter-yarn adhesion and interyarn sliding friction. It also reduced the tensile modulus of the yarn and increased deformability in the shear of the fabric [7]. In another study, it was demonstrated that the nature of the stick-slip motion of the dynamic frictional force of a pulled-out yarn was periodic and depended on yarn spacing in the fabric structure. There was a high correlation between yarn pull-out force, the intensity of thread interaction at the crossing points and the strength of fabric in the warp and weft directions $[8,9]$. The pull-out test was developed as a method of providing useful information about fabric mechanics, the finishing efficiency and its frictional behaviour [10].
Yarn pull-out from woven fabric was modelled, and it was claimed that the maximum pull-out load was related to yarn geometry and yarn mechanical properties, and the corresponding fabric density. In addition, it was shown that yarn pull-out depends on fabric weave structure and yarn types [11, 12]. The fabric displacement stage and crimp extension stage in single and multiple yarn ends pull-out have been investigated [13, 14]. It was concluded that the fabric displacement stage could be utilized to determine the fabric shear behaviour [15] and the crimp extension stage could be used to explain the fabric failure under tensile loads [16]. The stick-slip phenomenon has been identified in nature and has been used to explain the seismic movement, the flow of glaciers and textile materials, and even everyday life [17]. As seen in literature, the effect of friction in the stick-slip stage of pull-out in biaxial woven fabric was important for structural properties. Therefore, the aim of this study was to understand the effect of weaves on the stick-slip stage of single and multiple yarn pull-outs of polyester woven fabrics.

\section{Materials and Methods}

\section{Polyester woven fabrics}

Continuous filament polyester air-entangled textured yarn (Advansa, Turkey) was used to produce woven fabrics. The linear density of continuous filament air-entangled polyester textured yarn is 33.33 tex and has 68 filaments in a crosssection. It also has $10 / 10 \mathrm{~cm}$ entanglement. The woven fabrics were designed as $1 / 1$ plain, 2/2 warp ribs and 1/4 satin weaves. All the fabrics were produced by an air-jet weaving machine (Picanol Omni Plus-800, Belgium). The specifications of these woven fabrics are presented in Table 1. 
Table 1. Specifications of polyester woven fabrics.

\begin{tabular}{|c|c|c|c|c|c|c|c|c|c|}
\hline \multirow{2}{*}{ Fabric } & \multicolumn{2}{|c|}{ Yarn linear density (tex) } & \multicolumn{2}{|c|}{ Density (ends/cm) } & \multirow{2}{*}{ Weave type } & \multicolumn{2}{|c|}{ Crimp (\%) } & \multirow{2}{*}{$\begin{array}{l}\text { Mass } \\
\left(\mathrm{g} / \mathrm{m}^{2}\right)\end{array}$} & \multirow{2}{*}{$\begin{array}{l}\text { Thickness } \\
(\mathrm{mm})\end{array}$} \\
\hline & Weft & Warp & Weft & Warp & & Weft & Warp & & \\
\hline Plain fabric & 33.33 & 33.33 & 18 & 38 & Plain(1/1) & 4.62 & 20.08 & 219 & 0.57 \\
\hline Ribs fabric & 33.33 & 33.33 & 18 & 38 & $\operatorname{Ribs}(2 / 2)$ & 4.16 & 28.74 & 253 & 1.77 \\
\hline Satin fabric & 33.33 & 33.33 & 18 & 38 & Satin(1/4) & 11.00 & 22.18 & 247 & 1.06 \\
\hline
\end{tabular}

Fabric crimp measurement was performed using a Tautex digital instrument (James $\mathrm{H}$. Heal Co., UK) based on ISO 72113. The fabric thickness measurement was performed using an R\&B cloth thickness tester (James $\mathrm{H}$. Heal Co., UK) based on ISO 5084. The fabric weight measurement was performed based on ISO 6348 using an Ohaus Adventurer ${ }^{\mathrm{TM}}$ Pro AV812 (Ohaus Corp. USA) digital balance. The fabric's initial angle between warp and weft was measured by an optical microscope (Olympus SZ61-TR).

\section{Pull-out tests}

Pull-out tests were conducted to determine the yarn-to-yarn friction on single or multiple yarn ends in the frayed edge of the plain, ribs and satin fabric structures. For this reason, a pull-out fixture was developed. Figure 1 shows the fixture and the pull-out test carried out in the testing instrument. Fabric from both the edges was clamped. In this set-up, the fabric stick-slip stage was defined as "the end of one yarn set (either warp or weft) passes through from the each of consecutive intersecting points in the fabric during single or multiple yarn pull-out after the maximum pull-out force stage completed" [18]. Figure 2 shows the schematic views of the fixture and pull-out test during the stick-slip stage. In addition, "the pulled yarn end in the fabric is released from the each yarn which is normal to the pulled yarn direction in where the response of the

(a)

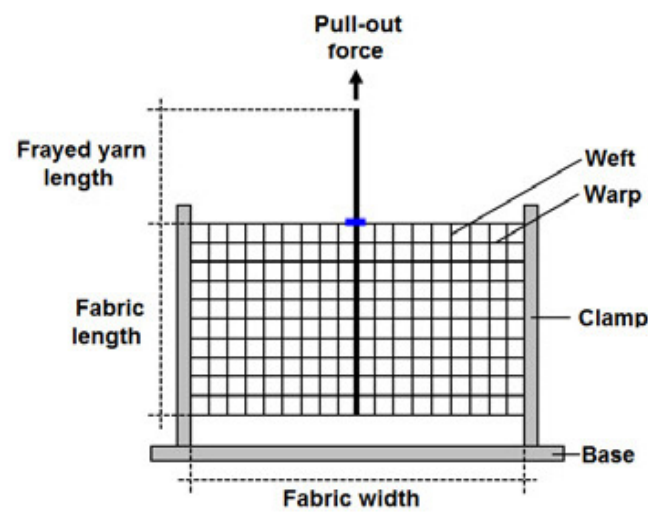

remaining part of the pulled yarn in the fabric is defined as the accumulative retraction force" [18]. Fabric crimp interchange during the pull-out test was ignored. The residual tension on the fabric due to clamped fabric edges was also ignored. The yarn slippages and yarn flattening in warp and weft directions in the fabric interlacement regions were not considered for

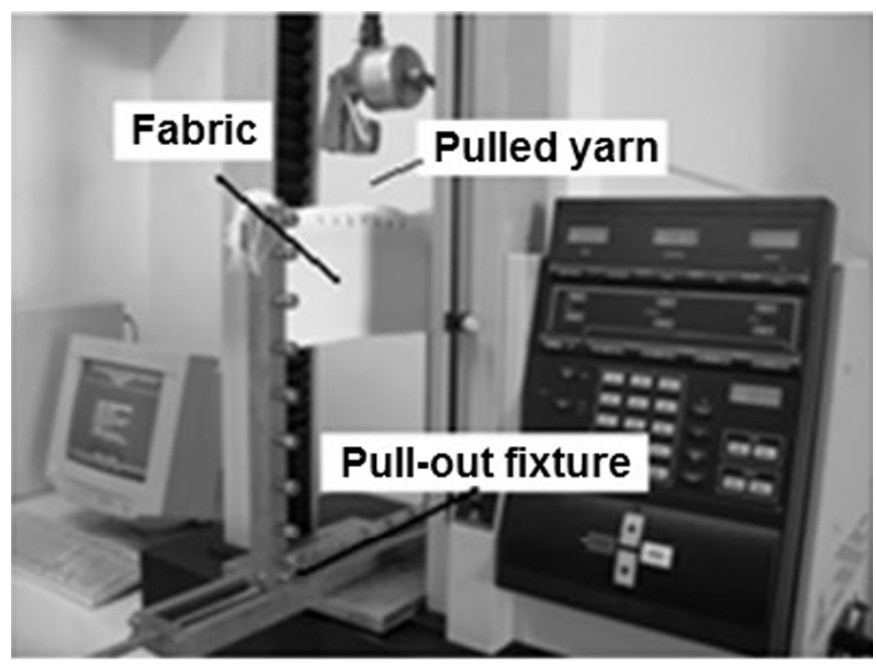

Figure 1. Pull-out fixture with fabric on the tensile testing instruments.

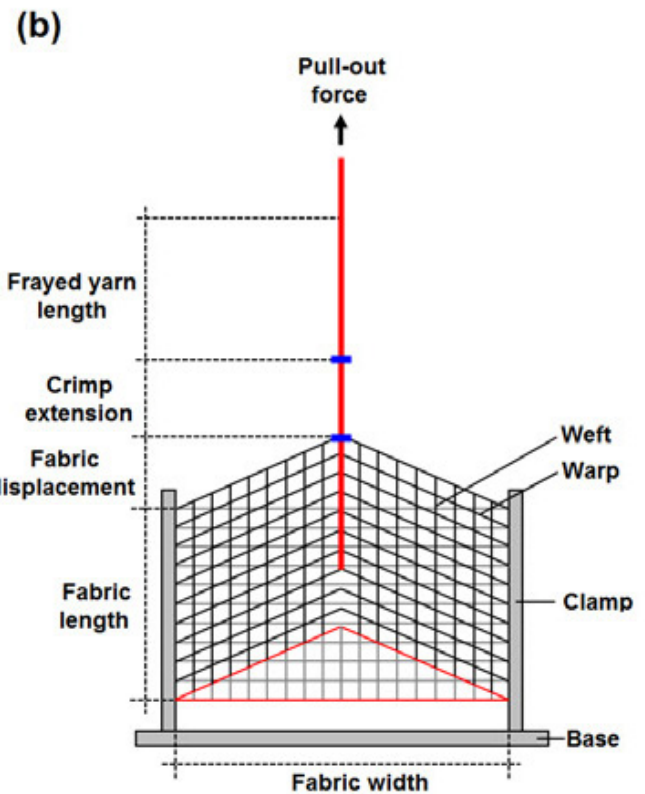

Figure 2. Schematic views of the fabric and yarn positions measured during pull-out test; a) fabric position before pull-out test and b) stick-slip stage of fabric position during pull-out test. 
simplification purposes. The testing instrument used was the Instron 4411 and the testing speed was $100 \mathrm{~mm} / \mathrm{min}$.

Fabric dimensions for performing the pull-out test were prepared. The fabric widths were 110 and $360 \mathrm{~mm}$ for the total sample dimension, and 50 and $300 \mathrm{~mm}$ for the sample dimension in the fixture, respectively. Fabric lengths were arranged 100 and $300 \mathrm{~mm}$ in all fabric widths. The pull-out direction was in the warp direction of the ribs and satin fabrics, whereas the pull-out direction was in the weft direction of the plain and satin fabrics. The frayed yarn length in the sample was $150 \mathrm{~mm}$ and the total edge length holding the sample in the fixture edge was $60 \mathrm{~mm}$. In the single yarn pull-out test, only one (1) yarn was pulled from the middle of the fabric sample. In the multiple yarn pull-out test, only five (5) yarn were pulled from the middle of the fabric sample. The Instron 4411 pull head draws individual yarn ends from the frayed edge of the single fabric. The force-displacement curve data obtained from single and multiple pull-outs were analysed by MATLABbased algorithm [19]. Using the algorithm, the stick-slip forces and accumulative retraction forces were calculated.

\section{Results and Discussion}

\section{Stick-Slip Stage in the Yarn Pull-Out}

Single and multiple yarn pull-out tests on polyester plain, ribs and satin woven fabric samples were carried out. Single and multiple yarn pull-out force-displacement curves were obtained. In the yarn pull-out force-displacement curve, the stick-slip stages of the kinetic friction part, which was from the beginning of the maximum pull-out force to the end of the yarn pull-out test, were considered. The curve in the kinetic region has one maxima and one minima for each two crossing points where from maximum to minimum (one minima) is called stick-slip and from minimum to maximum (one maxima) is called accumulative retraction force due to fabric structure. Figure 3 shows schematically the stick-slip stages of the single yarn pull-out force-displacement curve. The six meso-cells of polyester fabric in the bottom of the fabric edge (a) and middle of the fabric centre (b) were considered to investigate the stick-slip stage of the single and multiple yarn pull-out forcedisplacements.

If the one yarn set either warp or weft made one interlacement to the another one yarn set either weft or warp, this was defined as one meso cell as shown in Figure 4. One meso cell is composed of one stick region and one slip region as shown in Figure 4. In the stick region, there is pressure between the warp and weft yarns either in the front face or back face of the fabric during the pulling of the warp or weft yarns as shown schematically in Figure 5. In the slip region, there is pressure between the warp and weft yarns where the warp is crossed during the pulling of the warp yarn as shown in Figure 5 . The amount of pressure is proportional, as given in the following relationships.

$$
\begin{aligned}
& \mathrm{F}_{1}=\cos \theta \times \mathrm{F} \\
& \mathrm{F}_{2}=\sin \theta \times \mathrm{F}
\end{aligned}
$$

where $F$ is the pull-out force, $\theta$ is the initial crossing angle, $F_{1}$ is the in-plane direction pull-out force component and $F_{2}$ is

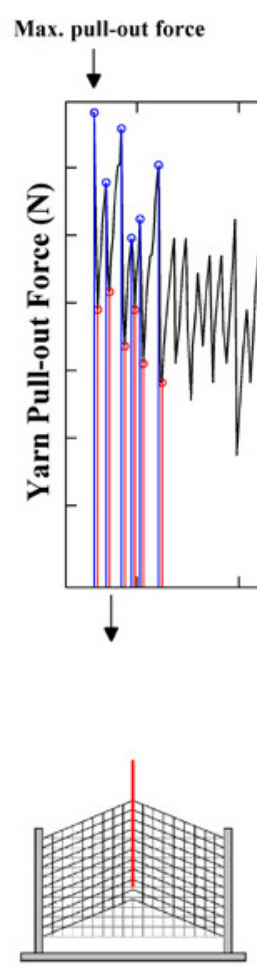

(a)

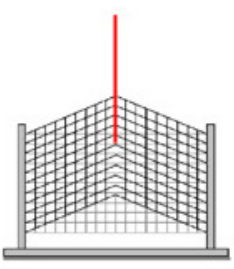

(b)

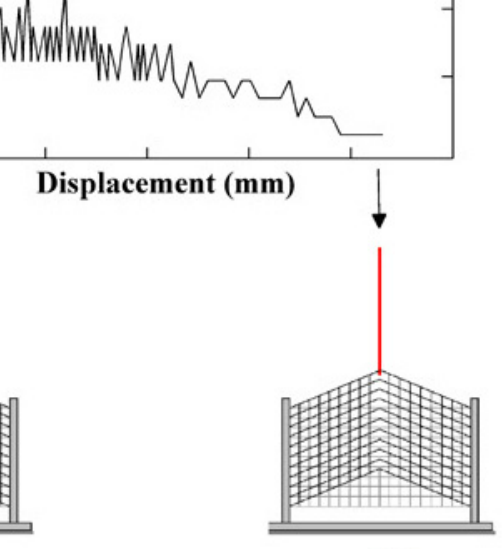

(c)

Figure 3. Stick-slip stage of single yarn pull-out force-displacement curves of woven fabric. a) The number of the meso-cells in the beginning of stick-slip stage at the bottom of the fabric edge, b) the number of meso-cells in the middle of the stick-slip stage at the centre of the fabric, c) the end of the stick-slip stage at the top of the fabric edge (plain fabric, pull-out direction: weft, number of pulled yarn:1, fabric width: $50 \mathrm{~mm}$, fabric length: $300 \mathrm{~mm}$ ). 
the out-of-plane direction pull-out force component. The initial crossing angle $(\theta)$ depends on directional fabric density and directional crimp ratio. Under the pull-out force on warp yarn, fabric displacement and crimp extension stages occurred first [13]. This causes straightening of the pulled warp yarn and $\theta$ is decreased from its initial value. The measured average initial warp angle, $\theta$, values for dry polyester fabrics were $37.16^{\circ}$ for plain weave, $38.28^{\circ}$ for ribs weave and $26.32^{\circ}$ for satin weave. If we use equations (1) and (2), we obtain $F_{1}=0.797 \times F$ and $F_{2}=0.604 \times F$ for dry plain fabric, $F_{1}=0.785 \times F$ and $F_{2}=0.620 \times F$ for dry ribs fabric, $F_{1}=0.896 \times F$ and $F_{2}=0.443 \times F$ for dry satin fabrics. As seen in the relations, the out-of-plane direction pullout force, $F_{2}$, was small and the in-plane direction pull-out force, $F_{1}$, was high for both fabric structures. In the stick regions, the in-plane direction pull-out force component $\left(F_{1}\right)$ is most likely to main force to generate pressure on the yarn in the fabric structure. In slip regions, out-of-plane direction pull-out force component $\left(F_{2}\right)$ is most likely to force to generate pressure on the crossing part of the yarn in the fabric structure as shown in Figures 4 and 5 . However, more research is required to define the yarn pressure in the slip region of the fabric during pull-out.
When we look at the meso-cells in the stick-slip stages of the single yarn pull-out force-displacement curve in Figure 3, there is an exponential function that has periodic decrease and increase lines. It is most likely that the decreasing line corresponds to each stick-slip region (Sk-Sp), whereas the increasing line corresponds to each accumulative retraction force by fabric structure (Af) as shown in Figure 6. After the maximum pull-out force stage was completed, the first decreasing line occurred due to the first yarn stick-slip region. When the first yarn (weft) was released from the fabric structure, the first increasing line occurred due to accumulative retraction force by fabric structure coming from the remaining five yarns in the end of the pulled yarn (warp) as shown in Figures 5 and 6 . When the pull-out phenomenon was repeated, the second decreasing line occurred due to the second yarn stick-slip region. Immediately afterwards, the second yarn was released from the fabric structure and the second increasing line occurred due to accumulative retraction force by the fabric structure coming from the remaining four yarns in the end of the pulled yarn. This phenomenon was repeated until the sixth yarn was released from the pulled yarn. (a)

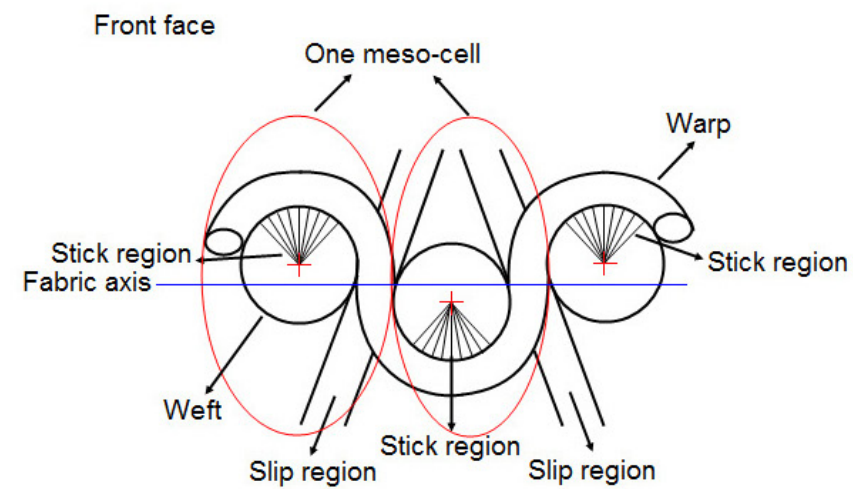

(b)

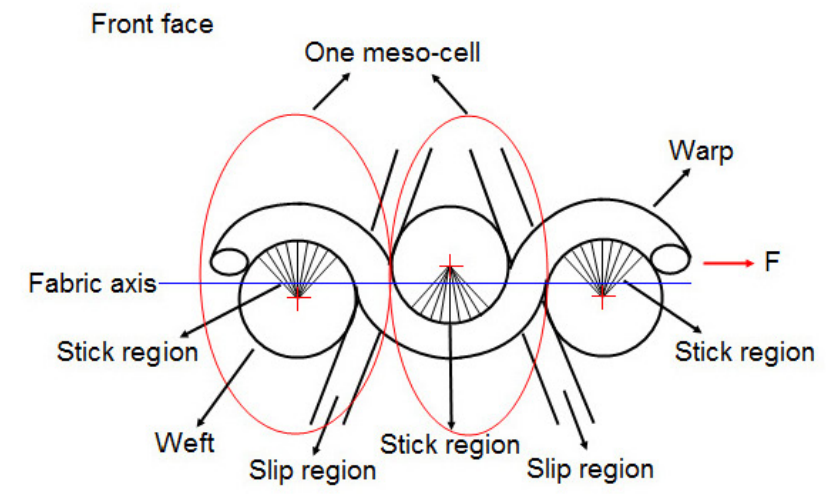

Back face

Back face

Figure 4. The schematic views of stick-slip stage in the meso-cells of fabric structures, a) before pull-out force is applied and b) after pull-out force is applied.

Front face

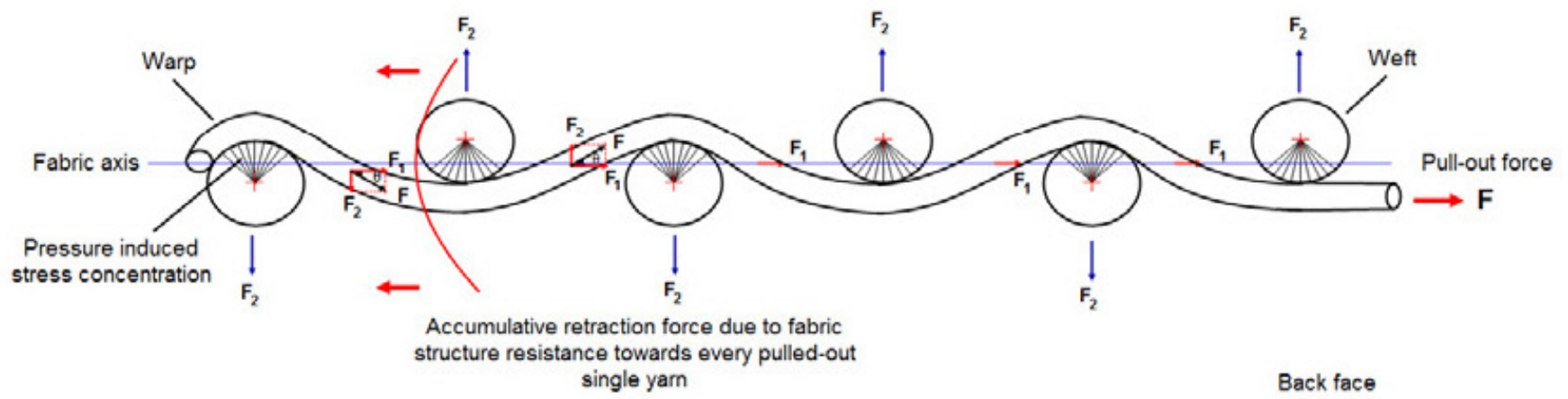

Figure 5. The schematical views of pull-out force components in stick-slip stage of the fabric. 


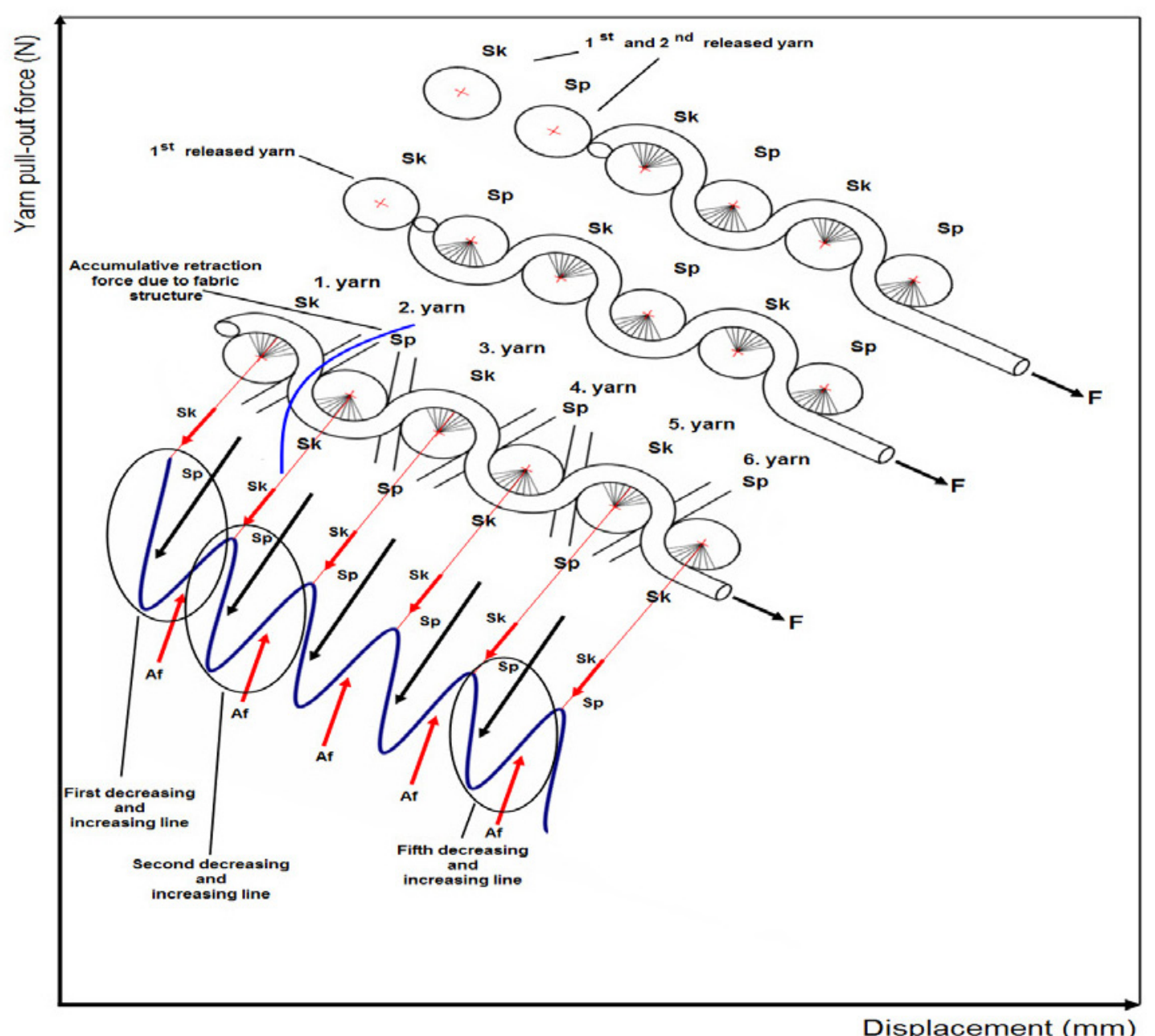

Figure 6. The schematic views of stick-slip stage in the representative pull-out force-displacement curve of fabric during pull-out.

\section{Stick-Slip Force in Single Yarn Pull-Out}

\section{Dry fabric}

Stick-slip force and accumulative retraction force obtained from the single yarn pull-out force-displacement curve of dry polyester plain, ribs and satin fabrics for six meso-cells in the fabric edge and fabric centre regions are presented in Tables 2 and 3 , respectively. Figure $7(a)$ and (b) shows the relationship between warp and weft directional stick-slip force and the number of meso-cells in the single yarn pull-out test of dry polyester plain, ribs and satin fabrics in the fabric edge and fabric centre regions, respectively.

As shown in Table 2, the warp directional single yarn stick-slip forces of dry ribs and satin narrow fabric varied from 0.40 to $1.34 \mathrm{~N}$ and 0.13 to $0.40 \mathrm{~N}$ in MC-1 to MC-6 for short fabric and from 0.54 to 1.75 and 0.94 to $1.88 \mathrm{~N}$ in $\mathrm{MC}-1$ to $\mathrm{MC}-6$ for long fabric in fabric edge region, respectively. However, the warp directional single yarn stick-slip forces of dry ribs and satin wide fabric varied from 0.67 to $1.75 \mathrm{~N}$ and 0.13 to $0.53 \mathrm{~N}$ in MC-1 to MC-6 for short fabric and from 0.14 to $2.68 \mathrm{~N}$ and 0.27 to $1.21 \mathrm{~N}$ in $\mathrm{MC}-1$ to $\mathrm{MC}-6$ for long fabric in fabric edge region, respectively. The weft directional single yarn stick-slip forces of dry plain and satin narrow fabric varied from 0.54 to $1.07 \mathrm{~N}$ and 0.13 to $0.27 \mathrm{~N}$ in MC-1 to MC-6 for short fabric and from 0.13 to 2.42 and 0.13 to $0.13 \mathrm{~N}$ in MC-1 to MC-6 for long fabric in fabric edge region, respectively. However, the weft directional single yarn stick-slip forces of dry plain and satin wide fabric varied from 0.53 to $1.61 \mathrm{~N}$ and 0.13 to $0.27 \mathrm{~N}$ in MC-1 to MC-6 for short fabric and from 0.13 to $1.61 \mathrm{~N}$ and 0.13 to $0.27 \mathrm{~N}$ in $\mathrm{MC}-1$ to $\mathrm{MC}-6$ for long fabric in fabric edge region, respectively.

As shown in Figure 7(a) and (b), the warp directional single yarn stick-slip forces in the MC- 1 to the MC- 6 of dry ribs fabrics in the wide $(300 \mathrm{~mm})$ and long $(300 \mathrm{~mm})$ fabric in fabric edge and centre were slightly higher than those in the satin fabric, whereas the weft directional single yarn stick-slip forces in the MC- 1 to the MC- 6 of dry plain fabrics in the wide and long fabric in fabric edge and centre were slightly higher than those in the satin fabric. In addition, the warp and weft directional single yarn stick-slip forces in the MC- 1 to the MC- 6 of dry plain, ribs and satin fabrics in the wide and narrow and short and long fabrics in fabric edge were slightly higher than those in the fabric centre. The warp directional single yarn stick-slip forces in the MC- 1 to the MC- 6 of dry wide and long satin fabric in fabric edge were slightly higher than those in the weft direction due to fabric density. 
Table 2. Stick-slip force and accumulative retraction force obtained from the single and multiple yarn pull-out force-displacement curves of dry polyester fabrics for six meso-cells in the fabric edge region.

\begin{tabular}{|c|c|c|c|c|c|c|c|c|c|c|c|c|c|c|c|c|}
\hline \multirow{4}{*}{ 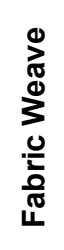 } & \multirow{4}{*}{ 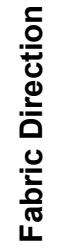 } & \multirow{4}{*}{$\begin{array}{l}\text { Fabric } \\
\text { width } \\
(\mathrm{mm})\end{array}$} & \multirow{4}{*}{$\begin{array}{l}\text { Fabric } \\
\text { length } \\
(\mathrm{mm})\end{array}$} & \multirow{4}{*}{$\begin{array}{l}\text { Ends } \\
\text { of yarn }\end{array}$} & \multicolumn{12}{|c|}{ Fabric Edge } \\
\hline & & & & & \multicolumn{2}{|c|}{ MC-1 } & \multicolumn{2}{|c|}{ MC-2 } & \multicolumn{2}{|c|}{ MC-3 } & \multicolumn{2}{|c|}{ MC-4 } & \multicolumn{2}{|c|}{ MC-5 } & \multicolumn{2}{|c|}{ MC-6 } \\
\hline & & & & & Sk-Sp & Af & Sk-Sp & Af & Sk-Sp & Af & Sk-Sp & Af & Sk-Sp & Af & Sk-Sp & Af \\
\hline & & & & & $(\mathrm{N})$ & $(\mathrm{N})$ & $(\mathrm{N})$ & (N) & (N) & $(\mathrm{N})$ & (N) & (N) & (N) & $(\mathrm{N})$ & (N) & $(\mathrm{N})$ \\
\hline \multirow{8}{*}{$\frac{\frac{5}{\pi}}{\frac{\pi}{\alpha}}$} & \multirow{8}{*}{ 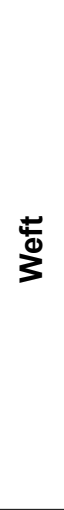 } & \multirow{4}{*}{50} & \multirow{2}{*}{100} & 1 yarn & 1.07 & 0.67 & 0.81 & 0.68 & 0.68 & 0.68 & 0.81 & 0.81 & 0.54 & 0.40 & 0.54 & 0.54 \\
\hline & & & & 5 yarns & 41.22 & 37.19 & 47.00 & 33.31 & 35.73 & 28.47 & 28.06 & 27.52 & 28.46 & 23.36 & 24.71 & 20.69 \\
\hline & & & \multirow{2}{*}{300} & 1 yarn & 1.08 & 1.08 & 1.62 & 1.48 & 0.13 & 0.27 & 2.42 & 2.01 & 2.01 & 2.01 & 1.88 & 1.75 \\
\hline & & & & 5 yarns & 47.54 & 9.14 & 10.48 & 7.26 & 8.06 & 9.13 & 8.87 & 9.55 & 10.48 & 8.73 & 8.73 & 7.66 \\
\hline & & \multirow{4}{*}{300} & \multirow{2}{*}{100} & 1 yarn & 1.47 & 0.94 & 0.81 & 1.21 & 1.61 & 0.80 & 0.53 & 0.67 & 1.07 & 1.47 & 1.61 & 1.07 \\
\hline & & & & 5 yarns & 43.91 & 28.87 & 34.91 & 26.72 & 28.46 & 16.92 & 17.06 & 6.04 & 7.78 & - & - & - \\
\hline & & & \multirow{2}{*}{300} & 1 yarn & 0.13 & 0.13 & 1.61 & 0.81 & 0.14 & 0.40 & 0.13 & 0.27 & 1.48 & 1.21 & 0.94 & 0.94 \\
\hline & & & & 5 yarns & 20.68 & 19.07 & 23.90 & 18.26 & 21.89 & 18.67 & 19.74 & 15.44 & 11.14 & 18.13 & 22.97 & 15.17 \\
\hline \multirow{8}{*}{$\stackrel{\mathscr{0}}{\bar{\alpha}}$} & \multirow{8}{*}{$\frac{\frac{0}{2}}{3}$} & \multirow{4}{*}{5} & & 1 yarn & 1.34 & 0.93 & 0.40 & 0.54 & 0.67 & 0.80 & 1.20 & 1.20 & 0.94 & 0.94 & 1.34 & 1.07 \\
\hline & & & $T$ & 5 yarns & 25.38 & 22.83 & 22.43 & 23.1 & 21.89 & 18.94 & 20.42 & 14.23 & 24.44 & 9.54 & 9.14 & 8.87 \\
\hline & & & 300 & 1 yarn & 1.34 & 0.81 & 0.67 & 1.20 & 1.34 & 0.81 & 0.54 & 0.81 & 1.75 & 1.48 & 0.54 & 0.81 \\
\hline & & & & 5 yarns & 38.27 & 5.37 & 7.79 & 7.25 & 5.23 & 6.31 & 6.99 & 8.06 & 7.66 & 7.80 & 7.39 & 8.73 \\
\hline & & & 100 & 1 yarn & 1.74 & 1.07 & 0.67 & 0.81 & 1.75 & 1.75 & 1.75 & 1.48 & 1.34 & 1.07 & 0.67 & 0.80 \\
\hline & & & 100 & 5 yarns & 33.98 & 16.92 & 14.49 & 14.49 & 20.28 & 15.72 & 21.09 & 15.85 & 16.65 & 9.40 & 8.06 & 4.83 \\
\hline & & 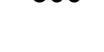 & & 1 yarn & 2.42 & 2.29 & 2.55 & 1.20 & 0.40 & 1.61 & 2.68 & 1.21 & 0.14 & 1.07 & 2.55 & 1.75 \\
\hline & & & & 5 yarns & 7.47 & 9.54 & 7.91 & 11.14 & 10.07 & 11.68 & 9.94 & 11.55 & 11.68 & 13.42 & 12.75 & 13.42 \\
\hline & & & & 1 yarn & 0.40 & 0.40 & 0.14 & 0.14 & 0.40 & 0.26 & 0.13 & 0.13 & 0.26 & 0.26 & 0.26 & 0.13 \\
\hline & & & & 5 yarns & 21.62 & 19.61 & 20.95 & 19.34 & 19.07 & 17.72 & 19.60 & 19.20 & 20.28 & 17.19 & 18.39 & 13.03 \\
\hline & & & & 1 yarn & 1.88 & 1.88 & 1.47 & 1.07 & 0.94 & 1.07 & 1.61 & 1.35 & 1.08 & 1.34 & 1.47 & 1.21 \\
\hline & 은 & & & 5 yarns & 35.44 & 17.58 & 15.03 & 9.93 & 7.79 & 6.45 & 9.00 & 8.46 & 6.44 & 9.12 & 10.33 & 6.44 \\
\hline & & & & 1 yarn & 0.53 & 0.27 & 0.14 & 0.14 & 0.14 & 0.40 & 0.13 & 0.13 & 0.40 & 0.14 & 0.27 & 0.40 \\
\hline & & & & 5 yarns & 16.39 & 11.83 & 14.78 & 9.54 & 9.81 & 8.07 & 9.54 & 6.71 & 8.59 & 5.77 & 6.04 & 4.56 \\
\hline & & & & 1 yarn & 1.21 & 0.81 & 0.81 & 0.54 & 0.27 & 0.81 & 1.21 & 0.80 & 0.80 & 0.54 & 0.27 & 0.27 \\
\hline$=$ & & & & 5 yarns & 28.87 & 24.85 & 27.67 & 26.73 & 27.66 & 27.12 & 29.81 & 19.6 & 17.45 & 20.68 & 26.05 & 22.68 \\
\hline$\ddot{\omega}$ & & & & 1 yarn & 0.14 & 0.14 & 0.14 & 0.14 & 0.14 & 0.14 & 0.27 & 0.13 & 0.13 & 0.13 & 0.13 & 0.13 \\
\hline & & & & 5 yarns & 2.15 & 0.40 & 0.67 & 0.27 & 0.81 & 0.54 & 0.54 & 0.41 & 0.54 & 0.40 & 0.54 & 0.27 \\
\hline & & 0 & & 1 yarn & 0.13 & 0.13 & 0.13 & 0.13 & 0.13 & 0.13 & 0.13 & 0.13 & 0.13 & 0.13 & 0.13 & 0.13 \\
\hline & $\frac{4}{4}$ & & & 5 yarns & 0.40 & 0.27 & 0.81 & 0.41 & 0.81 & 0.27 & 2.01 & 1.74 & 1.47 & 0.80 & 0.27 & 0.14 \\
\hline & & & & 1 yarn & 0.14 & 0.14 & 0.27 & 0.13 & 0.13 & 0.13 & 0.13 & 0.13 & 0.13 & 0.13 & 0.13 & 0.13 \\
\hline & & & & 5 yarns & 0.81 & 0.41 & 0.54 & 0.40 & 0.53 & 0.26 & 0.80 & 0.27 & 0.81 & 0.41 & 0.68 & 0.41 \\
\hline & & 80 & & arn & 0.13 & 0.13 & 0.13 & 0.13 & 0.13 & 0.13 & 0.13 & 0.13 & 0.27 & 0.14 & 0.14 & 0.14 \\
\hline & & & 000 & 5 yarns & 0.41 & 0.41 & 0.54 & 0.40 & 0.40 & 0.40 & 0.40 & 0.13 & 0.80 & 0.53 & 1.21 & 0.26 \\
\hline
\end{tabular}

MC: Meso-cell, Sk-Sp: Stick-Slip, Af: Accumulative retraction force due to fabric structure. 
Table 3. Stick-slip force and accumulative retraction force obtained from the single and multiple yarn pull-out force-displacement curves of dry polyester fabrics for six meso-cells in the fabric centre regions.

\begin{tabular}{|c|c|c|c|c|c|c|c|c|c|c|c|c|c|c|c|c|}
\hline \multirow{4}{*}{ 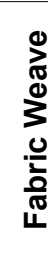 } & \multirow{4}{*}{ 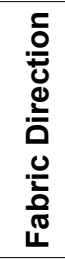 } & \multirow{4}{*}{$\begin{array}{l}\text { Fabric } \\
\text { width } \\
(\mathrm{mm})\end{array}$} & \multirow{4}{*}{$\begin{array}{c}\text { Fabric } \\
\text { length } \\
(\mathrm{mm})\end{array}$} & \multirow{4}{*}{$\begin{array}{l}\text { Ends } \\
\text { of yarn }\end{array}$} & \multicolumn{12}{|c|}{ Fabric Centre } \\
\hline & & & & & \multicolumn{2}{|c|}{ MC-1 } & \multicolumn{2}{|c|}{ MC-2 } & \multicolumn{2}{|c|}{ MC-3 } & \multicolumn{2}{|c|}{ MC-4 } & \multicolumn{2}{|c|}{ MC-5 } & \multicolumn{2}{|c|}{ MC-6 } \\
\hline & & & & & Sk-Sp & Af & Sk-Sp & Af & Sk-Sp & Af & Sk-Sp & Af & Sk-Sp & Af & Sk-Sp & Af \\
\hline & & & & & (N) & (N) & $(\mathrm{N})$ & (N) & (N) & (N) & (N) & (N) & $(\mathrm{N})$ & (N) & (N) & $(\mathrm{N})$ \\
\hline \multirow{8}{*}{$\frac{\frac{5}{\pi}}{\frac{\pi}{a}}$} & \multirow{8}{*}{$\frac{5}{30}$} & \multirow{4}{*}{50} & \multirow{2}{*}{100} & 1 yarn & 0.27 & 0.27 & 0.27 & 0.27 & 0.40 & 0.27 & 0.14 & 0.27 & 0.27 & 0.27 & 0.40 & 0.27 \\
\hline & & & & 5 yarns & 28.46 & 23.36 & 24.71 & 20.69 & 20.55 & 16.12 & 16.66 & 12.76 & 11.15 & 12.9 & 14.11 & 12.23 \\
\hline & & & \multirow{2}{*}{300} & 1 yarn & 1.21 & 1.07 & 0.94 & 0.81 & 0.94 & 1.07 & 1.07 & 1.07 & 1.20 & 1.07 & 0.94 & 0.81 \\
\hline & & & & 5 yarns & 3.76 & 1.62 & 1.35 & 1.75 & 4.57 & 5.37 & 5.90 & 4.43 & 3.63 & 3.76 & 4.43 & 5.91 \\
\hline & & \multirow{4}{*}{300} & \multirow{2}{*}{100} & 1 yarn & 0.54 & 0.54 & 0.80 & 0.80 & 0.80 & 0.80 & 0.94 & 0.81 & 0.67 & 0.67 & 0.67 & 0.53 \\
\hline & & & & 5 yarns & - & - & - & - & - & - & - & - & - & - & - & - \\
\hline & & & \multirow{2}{*}{300} & 1 yarn & 0.26 & 0.53 & 0.80 & 0.94 & 1.08 & 0.81 & 0.67 & 0.40 & 0.27 & 0.54 & 0.54 & 0.40 \\
\hline & & & & 5 yarns & 14.10 & 13.83 & 13.30 & 11.15 & 12.62 & 11.01 & 7.65 & 11.14 & 13.43 & 10.34 & 12.09 & 10.35 \\
\hline \multirow{8}{*}{$\stackrel{\mathscr{n}}{\underline{\alpha}}$} & \multirow{8}{*}{$\frac{2}{\frac{2}{3}}$} & \multirow{4}{*}{50} & & 1 yarn & 0.67 & 0.54 & 0.54 & 0.54 & 0.67 & 0.40 & 0.27 & 0.27 & 0.27 & 0.54 & 0.40 & 0.27 \\
\hline & & & & 5 yarns & 1.34 & 2.82 & 4.16 & 3.49 & 2.68 & 2.95 & 3.36 & 2.69 & 5.77 & 2.95 & 2.01 & 2.68 \\
\hline & & & 3 & 1 yarn & 1.75 & 1.48 & 1.48 & 1.61 & 1.34 & 0.81 & 0.94 & 0.80 & 0.40 & 1.21 & 1.88 & 1.48 \\
\hline & & & 000 & 5 yarns & 7.11 & 6.71 & 7.11 & 6.71 & 6.98 & 7.52 & 7.25 & 4.16 & 4.16 & 5.23 & 5.77 & 5.10 \\
\hline & & & & 1 yarn & 0.67 & 0.80 & 0.80 & 0.54 & 0.68 & 0.81 & 0.81 & 0.54 & 0.54 & 0.41 & 0.41 & 0.27 \\
\hline & & & 100 & 5 yarns & 8.06 & 4.83 & 5.37 & 5.11 & 4.17 & 4.57 & 7.25 & 4.16 & 3.89 & 2.01 & 2.68 & 1.34 \\
\hline & & 0 & & 1 yarn & 1.21 & 1.47 & 1.74 & 1.48 & 1.48 & 1.48 & 1.08 & 0.54 & 0.94 & 1.21 & 1.34 & 1.20 \\
\hline & & & 300 & 5 yarns & - & - & - & - & - & - & - & - & - & - & - & - \\
\hline & & & & 1 yarn & 0.27 & 0.27 & 0.14 & 0.14 & 0.27 & 0.27 & 0.40 & 0.40 & 0.27 & 0.27 & 0.14 & 0.14 \\
\hline & & 5 & 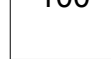 & 5 yarns & 4.03 & 4.57 & 3.49 & 4.02 & 5.90 & 6.04 & 5.91 & 4.43 & 2.15 & 1.08 & 2.55 & 3.89 \\
\hline & & 4 & & 1 yarn & 1.07 & 0.80 & 0.54 & 0.81 & 0.94 & 0.54 & 0.41 & 0.54 & 0.67 & 0.54 & 0.67 & 0.80 \\
\hline & 는 & & & 5 yarns & 5.91 & 6.72 & 8.07 & 7.26 & 7.39 & 7.39 & 7.53 & 7.26 & 6.99 & 6.46 & 4.31 & 4.84 \\
\hline & & & & 1 yarn & 0.40 & 0.27 & 0.27 & 0.27 & 0.27 & 0.27 & 0.40 & 0.26 & 0.13 & 0.13 & 0.13 & 0.13 \\
\hline & & & 100 & 5 yarns & - & - & - & - & - & - & - & 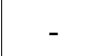 & - & - & - & - \\
\hline & & 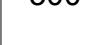 & & 1 yarn & 0.54 & 0.54 & 0.27 & 0.53 & 0.67 & 0.54 & 0.54 & 0.54 & 0.40 & 0.27 & 0.54 & 0.80 \\
\hline & & & 300 & 5 yarns & 21.63 & 16.66 & 17.46 & 16.65 & 16.65 & 16.25 & 19.20 & 15.04 & 15.45 & 9.28 & 8.74 & 6.44 \\
\hline & & & & 1 yarn & 0.13 & 0.13 & 0.27 & 0.27 & 0.27 & 0.27 & 0.13 & 0.13 & 0.13 & 0.13 & 0.13 & 0.13 \\
\hline & & & 15 & 5 yarns & 1.89 & 1.76 & 2.28 & 2.01 & 1.88 & 1.61 & 1.88 & 1.75 & 1.21 & 0.81 & 0.81 & 1.88 \\
\hline & & 50 & & 1 yarn & 0.27 & 0.27 & 0.41 & 0.41 & 0.27 & 0.27 & 0.41 & 0.54 & 0.54 & 0.54 & 0.54 & 0.41 \\
\hline & 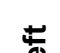 & & 50 & 5 yarns & 6.44 & 6.71 & 7.11 & 4.83 & 3.89 & 4.96 & 5.77 & 4.70 & 4.57 & 3.49 & 3.89 & 6.18 \\
\hline & & & 10 & 1 yarn & 0.13 & 0.26 & 0.26 & 0.13 & 0.27 & 0.27 & 0.27 & 0.27 & 0.13 & 0.13 & 0.13 & 0.13 \\
\hline & & & 100 & 5 yarns & 4.56 & 3.09 & 2.96 & 2.55 & 2.95 & 2.01 & 2.68 & 1.88 & 2.01 & 1.07 & 1.07 & 1.07 \\
\hline & & 30 & & 1 yarn & 0.27 & 0.41 & 0.41 & 0.27 & 0.13 & 0.27 & 0.41 & 0.27 & 0.27 & 0.41 & 0.41 & 0.27 \\
\hline & & & & 5 yarns & 0.80 & 0.53 & 0.13 & 0.40 & 0.80 & 0.53 & 0.13 & 0.40 & 0.80 & 0.53 & 0.13 & 0.40 \\
\hline
\end{tabular}


(a)

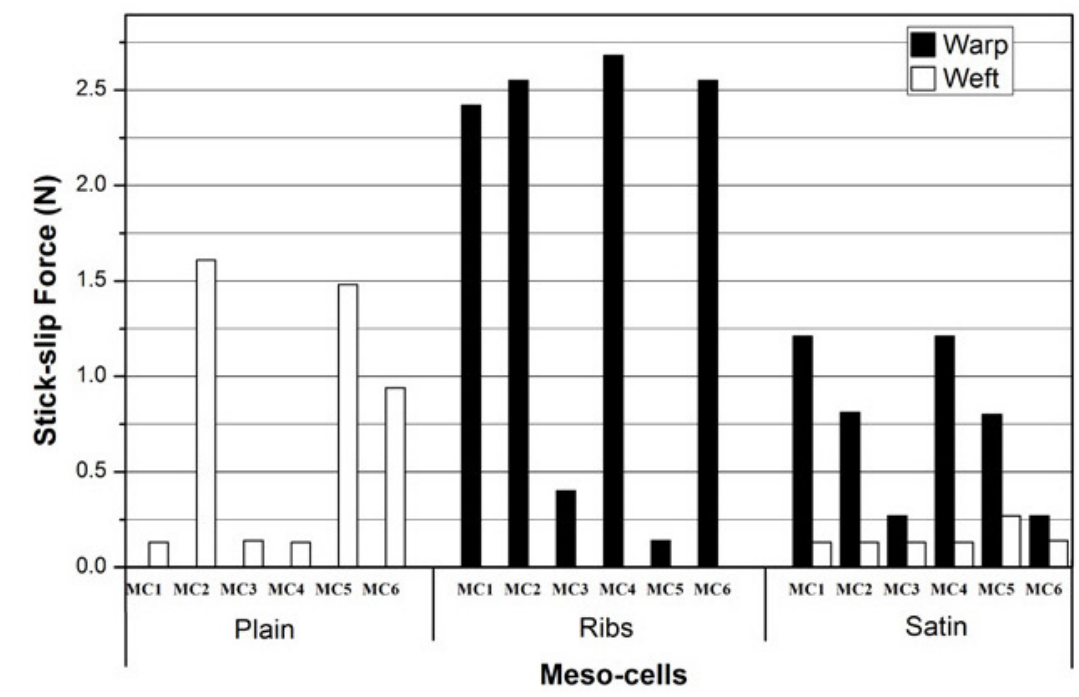

(b)

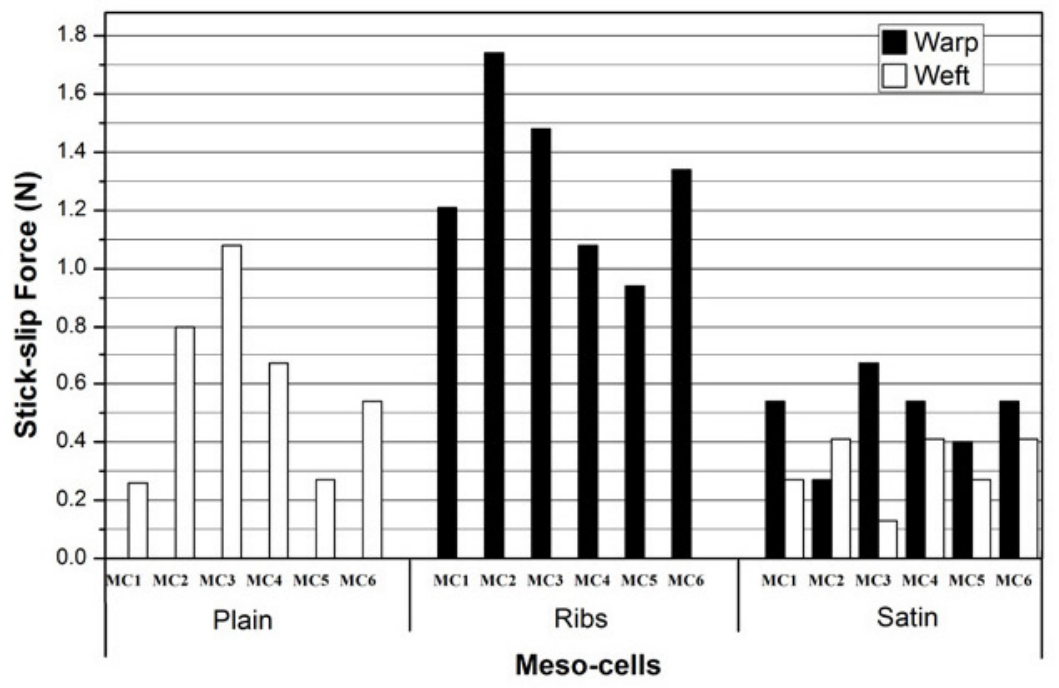

Figure 7. Relationship between stick-slip force and the number of meso-cells in single yarn pull-out test of dry polyester fabrics; fabric edge region (a) and fabric centre region (b) (sample width: $300 \mathrm{~mm}$ and length: $300 \mathrm{~mm}$ ).

\section{Accumulative Retraction Force Due To Fabric Structure In Single Yarn Pull-Out}

\section{Dry fabric}

Figure 8(a) and (b) shows the relationship between warp and weft directional accumulative retraction forces due to fabric structure and the number of meso-cells in the single yarn pullout test of dry polyester plain, ribs and satin fabrics in the fabric edge and fabric centre regions, respectively. As seen in Table 2, the warp directional single yarn accumulative retraction forces of dry ribs and satin narrow fabric varied from 0.54 to $1.20 \mathrm{~N}$ and 0.13 to $0.40 \mathrm{~N}$ in MC-1 to MC-6 for short fabric and from 0.81 to 1.48 and 1.07 to $1.88 \mathrm{~N}$ in MC-1 to MC-6 for long fabric in fabric edge region, respectively. However, the warp directional single yarn accumulative retraction forces of dry ribs and satin wide fabric varied from 0.80 to $1.75 \mathrm{~N}$ and 0.13 to $0.40 \mathrm{~N}$ in
MC-1 to MC-6 for short fabric and from 1.07 to $2.29 \mathrm{~N}$ and 0.27 to $0.81 \mathrm{~N}$ in $\mathrm{MC}-1$ to $\mathrm{MC}-6$ for long fabric in fabric edge region, respectively. The weft directional single yarn accumulative retraction forces of dry plain and satin narrow fabric varied from 0.40 to $0.81 \mathrm{~N}$ and 0.13 to $0.14 \mathrm{~N}$ in MC-1 to MC-6 for short fabric and from 0.27 to 2.01 and 0.13 to $0.13 \mathrm{~N}$ in MC-1 to MC-6 for long fabric in fabric edge region, respectively. However, the weft directional single yarn accumulative retraction forces of dry plain and satin wide fabric varied from 0.67 to $1.47 \mathrm{~N}$ and 0.13 to $0.14 \mathrm{~N}$ in MC-1 to MC-6 for short fabric and from 0.13 to $1.21 \mathrm{~N}$ and 0.13 to $0.14 \mathrm{~N}$ in MC-1 to MC-6 for long fabric in fabric edge region, respectively. As seen in Figure 8(a) and (b), the warp directional single yarn accumulative retraction forces in the MC- 1 to the MC- 6 of dry ribs fabrics in the wide $(300 \mathrm{~mm})$ and long $(300 \mathrm{~mm})$ fabric in fabric edge and centre regions were slightly higher than those in the satin fabric, whereas the weft directional single yarn accumulative retraction forces in 
(a)

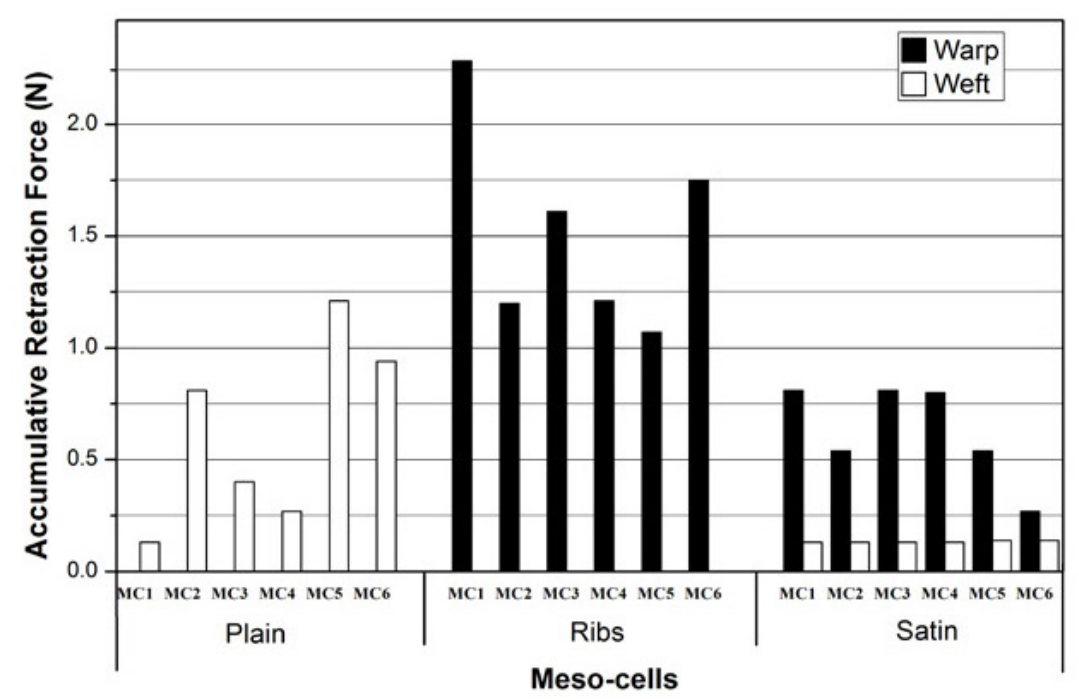

(b)

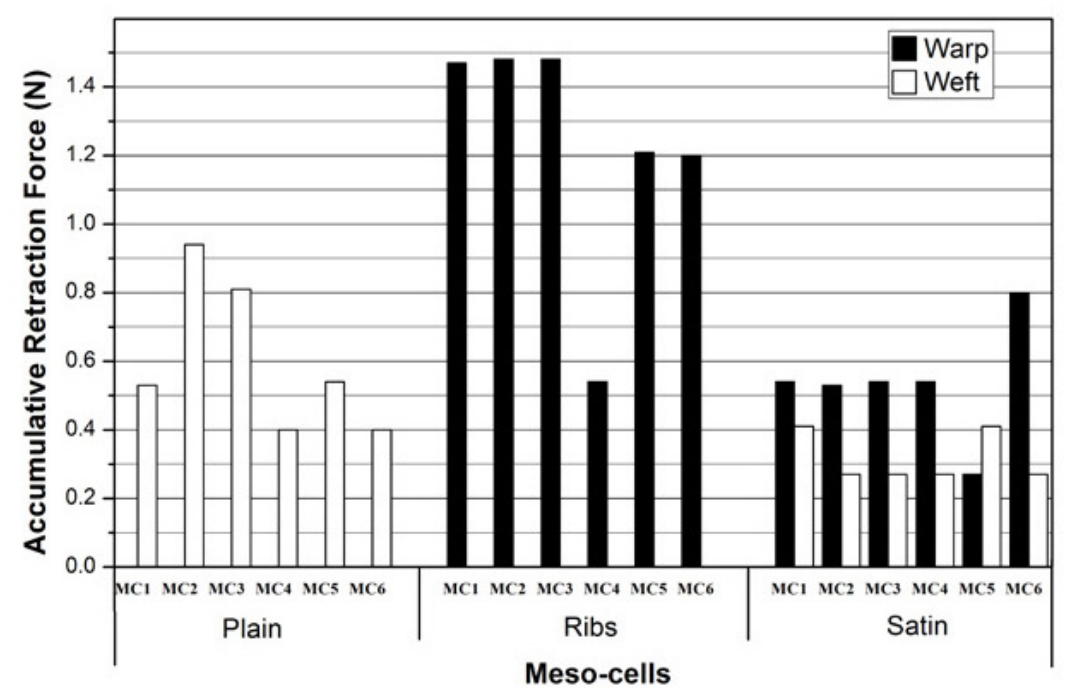

Figure 8. Relationship between accumulative retraction force due to fabric structure and the number of meso-cells in single yarn pull-out test of dry polyester fabrics; fabric edge region (a) and fabric centre region (b). (sample width: $300 \mathrm{~mm}$, length: $300 \mathrm{~mm}$ ).

the MC-1 to the MC-6 of dry plain fabrics in the wide and long fabric in fabric edge and centre regions were slightly higher than those in the satin fabric. In addition, the warp directional single yarn accumulative retraction forces in the MC- 1 to the MC- 6 of dry wide and long satin fabric in fabric edge were slightly higher than those in the weft direction due to fabric density. The warp and weft directional single yarn accumulative retraction forces in the MC- 1 to the MC- 6 of dry plain, ribs and satin fabrics in the wide and narrow and short and long fabrics in fabric edge were slightly higher than those in the fabric centre region.

\section{Stick-Slip Force in Multiple Yarn Pull-Out}

\section{Dry fabric}

Stick-slip force and accumulative retraction force obtained from the multiple yarn pull-out force-displacement curves of dry polyester plain, ribs and satin fabrics for six meso-cells are presented in Tables 2 and 3, respectively. Figure 9(a) and (b) shows the relationship between warp and weft directional stick-slip force and the number of meso-cells in the multiple yarn pull-out test of dry polyester plain, ribs and satin fabrics in fabric edge and centre regions, respectively. As seen in Table 2 , the warp directional multiple yarn stick-slip forces of dry ribs and satin narrow fabric varied from 9.14 to $25.38 \mathrm{~N}$ and 18.39 to $21.62 \mathrm{~N}$ in MC-1 to MC-6 for short fabric and from 5.23 to 38.27 and 6.44 to $35.44 \mathrm{~N}$ in MC-1 to MC-6 for long fabric in fabric edge region, respectively. However, the warp directional multiple yarn stick-slip forces of dry ribs and satin wide fabric varied from 8.06 to $33.98 \mathrm{~N}$ and 6.04 to $16.39 \mathrm{~N}$ in MC-1 to MC-6 for short fabric and from 7.91 to $37.47 \mathrm{~N}$ and 17.45 to $29.81 \mathrm{~N}$ in MC-1 to MC-6 for long fabric in fabric edge region, respectively. The weft directional multiple yarn stick-slip forces of dry plain and satin narrow fabric varied from 24.71 to 47.00 
$\mathrm{N}$ and 0.54 to $2.15 \mathrm{~N}$ in MC-1 to MC-6 for short fabric and from 8.06 to 47.54 and 0.27 to $2.01 \mathrm{~N}$ in MC-1 to MC-6 for long fabric in fabric edge region, respectively. However, the weft directional multiple yarn stick-slip forces of dry plain and satin wide fabric varied from 7.78 to $43.91 \mathrm{~N}$ and 0.53 to 0.81 $\mathrm{N}$ in MC-1 to MC-6 for short fabric and from 11.14 to $23.90 \mathrm{~N}$ and 0.40 to $1.21 \mathrm{~N}$ in MC-1 to MC-6 for long fabric in fabric edge region, respectively. As seen in Figure $9(\mathrm{a})$ and (b), the warp directional multiple yarn stick-slip forces in the MC-1 to the MC- 6 of dry satin fabrics in the wide $(300 \mathrm{~mm})$ and long $(300 \mathrm{~mm})$ fabric in fabric edge were higher than those in the ribs fabric except MC-1, whereas the weft directional multiple yarn stick-slip forces in the MC-1 to the MC- 6 of dry plain fabrics in the wide and long fabric in fabric edge and centre regions were higher than those in the satin fabric. In addition, the warp and weft directional multiple yarn stick-slip forces in the MC-1 to the MC- 6 of dry plain, ribs and satin fabrics in the wide and narrow and short and long fabrics in fabric edge were higher than those in the fabric centre region due to the number of crossing. The warp directional single yarn stick-slip forces in the MC- 1 to the MC- 6 of dry wide and long satin fabric in fabric edge and centre regions were higher than those in the weft direction due to fabric density. The warp and weft directional multiple yarn stick-slip forces in wide and narrow and long and short fabrics of dry plain, ribs and satin fabrics in fabric edge and centre regions were higher than those of the single yarn stick-slip forces.

\section{Accumulative Retraction Force Due To Fabric Structure in Multiple Yarn Pull-Out}

\section{Dry fabric}

Figure 10 (a) and (b) shows the relationship between warp and weft directional accumulative retraction forces due to fabric structure and the number of meso-cells in the multiple yarn

(a)

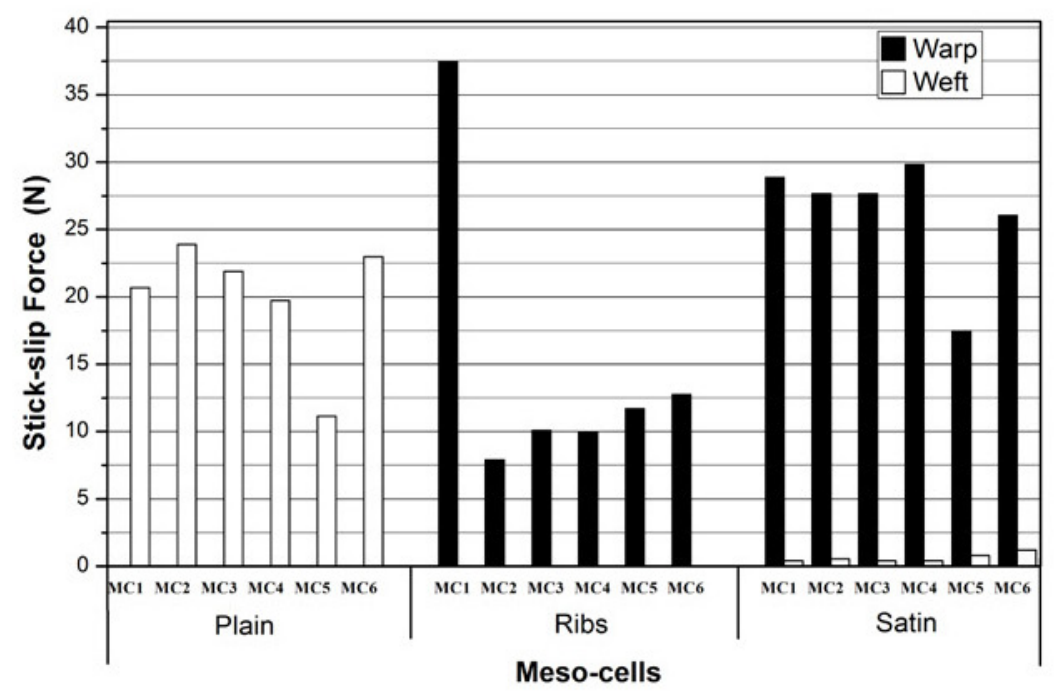

(b)

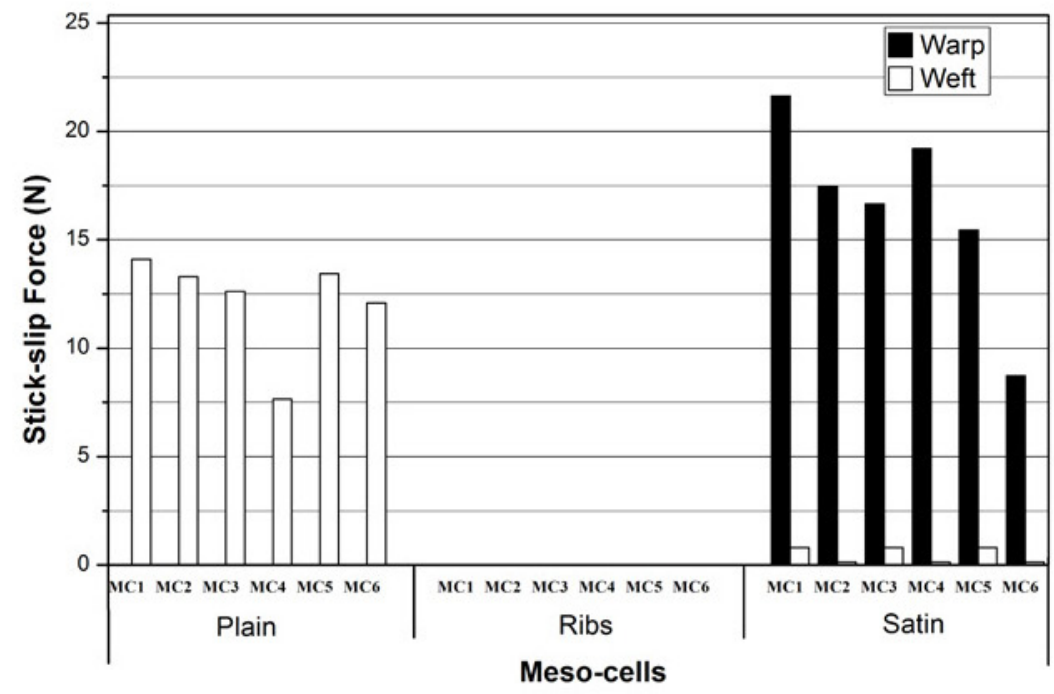

Figure 9. Relationship between stick-slip force and the number of meso-cells in multiple yarn pull-out test of dry polyester fabrics; fabric edge region (a) and fabric centre region (b) (pulled yarn ends: 5, sample width: $300 \mathrm{~mm}$, length: $300 \mathrm{~mm}$ ). 
pull-out test of dry polyester plain, ribs and satin fabrics in the fabric edge and fabric centre regions, respectively. As shown in Table 2, the warp directional multiple yarn accumulative retraction forces of dry ribs and satin narrow fabric varied from 8.87 to $23.10 \mathrm{~N}$ and 13.03 to $19.63 \mathrm{~N}$ in MC- 1 to MC-6 for short fabric and from 5.37 to 8.73 and 6.44 to $17.58 \mathrm{~N}$ in MC-1 to MC-6 for long fabric in fabric edge region, respectively. However, the warp directional multiple yarn accumulative retraction forces of dry ribs and satin wide fabric varied from 4.83 to $16.92 \mathrm{~N}$ and 4.56 to $11.83 \mathrm{~N}$ in MC-1 to MC-6 for short fabric and from 9.54 to $13.42 \mathrm{~N}$ and 19.60 to $27.12 \mathrm{~N}$ in MC-1 to MC-6 for long fabric in fabric edge region, respectively. The weft directional multiple yarn accumulative retraction forces of dry plain and satin narrow fabric varied from 20.69 to 37.19 $\mathrm{N}$ and 0.27 to $0.54 \mathrm{~N}$ in MC-1 to MC-6 for short fabric and from 7.26 to 9.55 and 0.14 to $1.74 \mathrm{~N}$ in MC-1 to MC-6 for long fabric in fabric edge region, respectively. However, the weft directional multiple yarn accumulative retraction forces of dry plain and satin wide fabric varied from 6.04 to $28.87 \mathrm{~N}$ and 0.26 to $0.41 \mathrm{~N}$ in MC-1 to MC-6 for short fabric and from 15.17 to $19.07 \mathrm{~N}$ and 0.13 to $0.53 \mathrm{~N}$ in MC-1 to MC-6 for long fabric in fabric edge region, respectively. As seen in Figure $10(a)$ and (b), the warp directional multiple yarn accumulative retraction forces in the MC- 1 to the MC- 6 of dry satin fabrics in the wide and long fabric in fabric edge were higher than those in the ribs fabric, whereas the weft directional multiple yarn stick-slip forces in the MC-1 to the MC- 6 of dry plain fabrics in the wide and long fabric in fabric edge and centre regions were higher than those in the satin fabric. The warp directional multiple yarn accumulative retraction forces in the MC- 1 to the MC- 6 of dry satin fabrics in the wide and long fabric in fabric edge and centre region were higher than those in the weft direction due to fabric density. In addition, the warp and weft directional multiple yarn accumulative retraction forces in the MC-1 to the MC- 6 of dry plain and satin fabrics in the wide and narrow and short and long fabrics in fabric edge

(a)

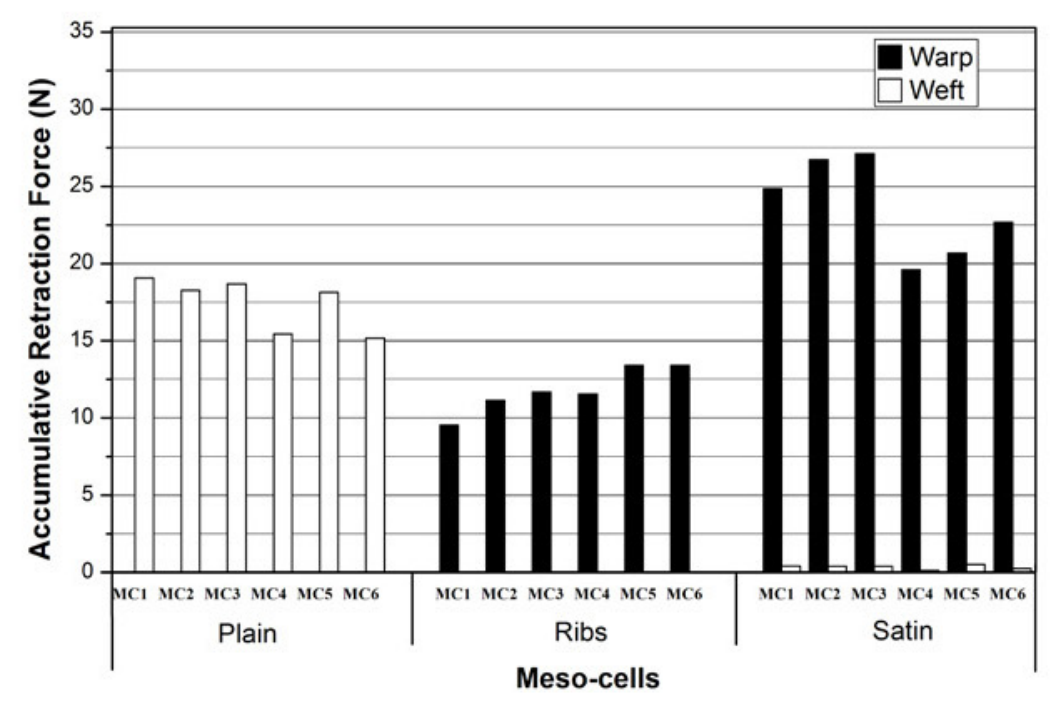

(b)

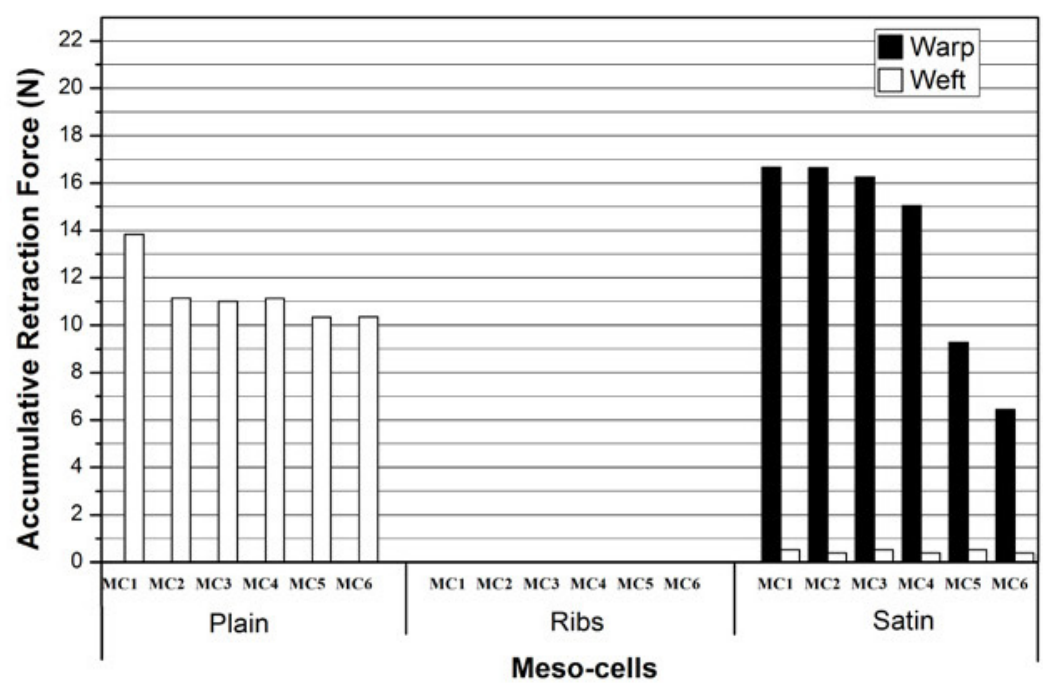

Figure 10. Relationship between accumulative retraction force due to fabric structure and the number of meso-cells in multiple yarn pull-out test of dry polyester fabrics; fabric edge region (a) and fabric centre region (b) (pulled yarn ends: 5 , sample width: 300 mm, length: 300 mm). 
were higher than those in the fabric centre region due to the number of crossing. The warp and weft directional multiple yarn accumulative retraction forces in wide and narrow and long and short fabrics of dry plain, ribs and satin fabrics in fabric edge and centre regions were higher than those of the single yarn accumulative retraction forces.

\section{General results}

General results are presented in Figure 11(a) and (b). The results of the study showed that stick-slip and accumulative retraction forces basically depends on fabric weave, fabric density, number of pulled yarn ends and sample dimensions. In general, the multiple yarn stick-slip and accumulative retraction forces of polyester fabrics were higher than those of single yarn stick-slip and accumulative retraction forces of polyester fabric. It was also found that stick-slip force and accumulative retraction force are proportional. The position of the mesocells affected the stick-slip and accumulative retraction forces of polyester fabrics. The multiple yarn stick-slip force in MC-1 was almost the highest. On the other hand, the stick-slip and accumulative retraction forces in fabric edge were higher than those of fabric centre region. As shown in Figure 11(a) and (b), the warp directional stick-slip and accumulative retraction forces of dry polyester fabrics were higher than those of weft directional stick-slip and accumulative retraction forces of polyester fabrics due to the high fabric density in warp direction. Although, the weft directional single yarn stick-slip forces of plain fabric are slightly higher than those of satin fabrics, the weft directional multiple yarn stick-slip forces of plain fabric are substantially higher than those of satin fabrics due to the high number of crossing in plain weave. The sample dimensions slightly affected the single and multiple yarn stick-slip and accumulative retraction forces.

\section{(a)}

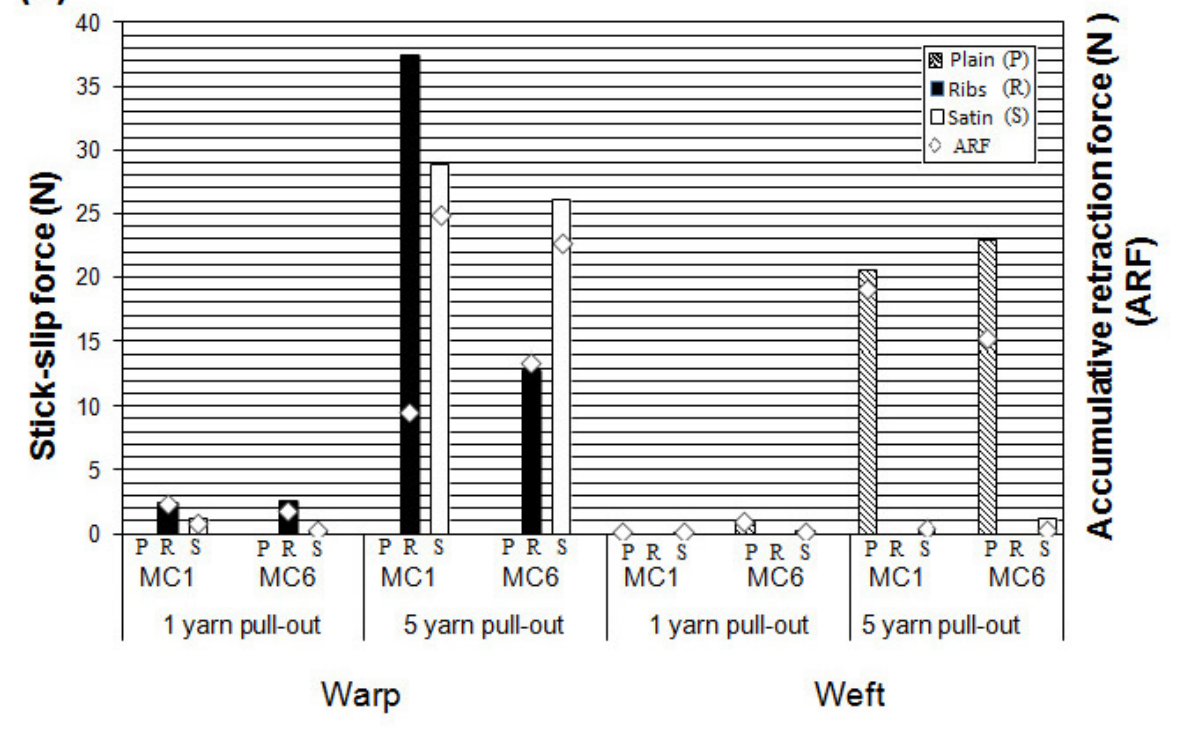

(b)

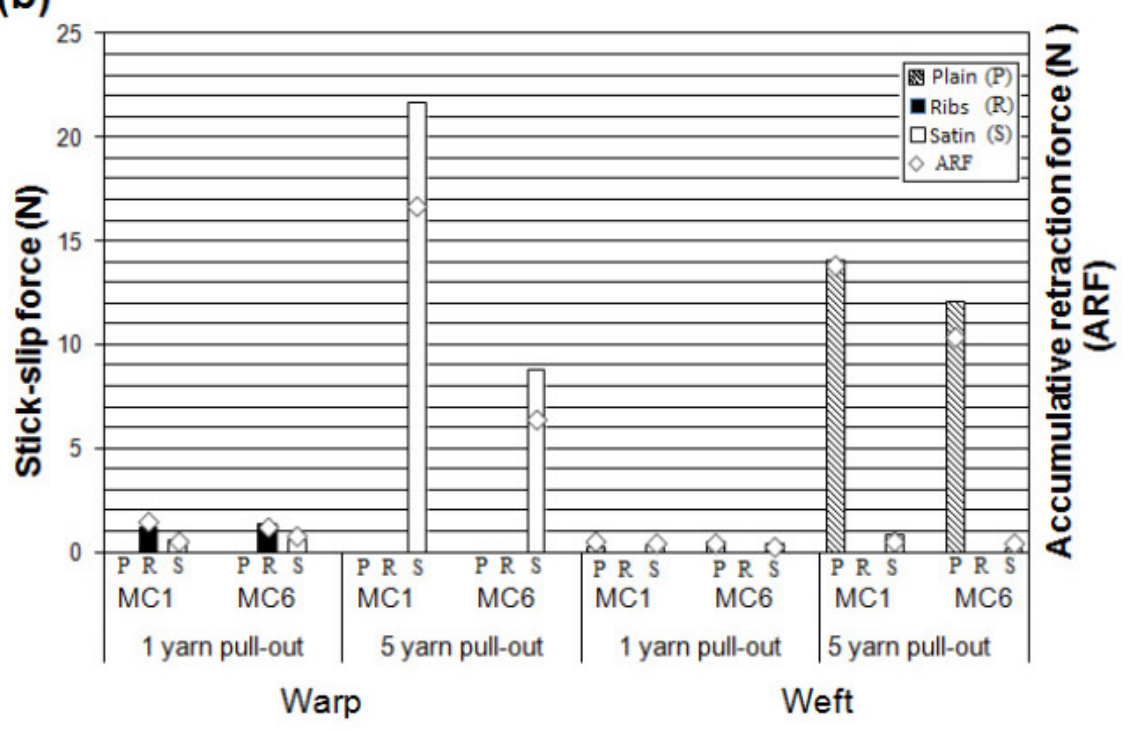

Figure 11. Relationships between stick-slip force and accumulative retraction force by single and multiple yarn pull-out in warp and weft directions of plain, ribs and satin weaves of dry polyester fabrics; fabric edge region (a) and fabric centre region (b) (sample width: $300 \mathrm{~mm}$, length: $300 \mathrm{~mm}$ ). 


\section{Conclusions}

Single and multiple yarn pull-out tests were conducted to understand the stick-slip properties of polyester fabric. Data were generated from single and multiple yarn ends pull-out tests for dry various polyester fabric weave.

It was found that the decreasing line in the force-displacement curve corresponds to each stick-slip region (Sk-Sp), whereas the increasing line in the force-displacement curve corresponds to each accumulative retraction force by fabric structure (Af). The amount of stick-slip force and accumulative retraction force in single and multiple yarn pull-out were extremely nonlinear. The MC-1 was found the most critical cell due to the starting point of the yarn pulling region and it was related to fabric boundary. On the other hand, the amount of stick-slip force was related to the number of interlacement points in the fabric, whereas the amount of accumulative retraction force was related to fabric structural response.

The weft directional single and multiple yarn stick-slip and accumulative retraction forces in the MC- 1 to the MC- 6 of dry plain fabrics in the wide and long fabric in fabric edge and centre were slightly higher than those in the satin fabric due to fabric weave. The warp and weft directional single and multiple yarn stick-slip and accumulative retraction forces in the MC-1 to the MC- 6 of dry plain, ribs and satin fabrics in the wide and narrow and short and long fabrics in fabric edge were slightly higher than those in the fabric centre due to the number of crossing. In addition, the warp directional single and multiple yarn stickslip and accumulative retraction forces in the MC- 1 to the MC- 6 of dry wide and long satin fabric in fabric edge were slightly higher than those in the weft direction due to fabric density. The warp and weft directional multiple yarn stick-slip and accumulative retraction forces in wide and narrow and long and short fabrics of dry plain, ribs and satin fabrics in fabric edge and centre regions were higher than those of the single yarn stick-slip and accumulative retraction forces due to number of pulled yarn ends. Future research should be conducted to find the analytical relation among stick-slip force, accumulative retraction force and yarn-fabric structural parameters for each fabric weave.

\section{Acknowledgements}

The author thank the research associates Mahmut Korkmaz and Dr. Bekir Yildirim for helping in some analyses on the subject.

\section{References}

[1] Sebastian, S.A.R.D., Bailey, Al., Briscoe, B.J., Tabor, D.: Extensions, Displacements and Forces Associated With Pulling A Single Yarn From A Fabric, Journal of Physics D: Applied Physics, Vol. 20, p. 130-139, ISSN 0022-3727, 1987.

[2] Gupta, B.S.: Friction in Textile Materials, Woodhead Publishing Limited, ISBN-13: 978-0849334788 (book), 2008

[3] Briscoe, B.J., Motamedi, F.: The Ballistic Impact
Characteristics of Aramid Fabrics: The Influence of Interface Friction, Wear, Vol. 158, p. 229-247, ISSN 00431648, 1992.

[4] Briscoe, B.J., Motamedi, F.: Role of Interfacial Friction and Lubrication in Yarn and Fabric Mechanics, Textile Research Journal, Vol. 60(12), p. 697-708, ISSN 0040-5175, 1990.

[5] Nikonova, E.A., Pakshver, A.B.: The Friction Properties of Textile Yarns, Fiber Chemistry, Vol. 4(6), p. 657-660, ISSN 0015-0541, 1973.

[6] Motamedi, F., Bailey, A.I., Briscoe, B.J., Tabor, D.: Theory and Practice of Localized Fabric Deformations, Textile Research Journal, Vol. 59, p. 160-172, ISSN 0040-5175, 1989.

[7] Sebastian, S.A.R.D., Bailey, A.I., Briscoe, B.J., Tabor, D.: Effect of a Softening Agent on Yarn Pull-Out Force of $A$ Plain Weave Fabric, Textile Research Journal, Vol. 56(10), p. 604-611, ISSN 0040-5175, 1986.

[8] Ravandi, S., Toriumi, K.: Spectral Analysis of the YarnPullout Force from Plain-Weave Fabric, Journal of the Textile Institute, Vol. 87(3), p. 522-531, ISSN 0040-5000, 1996.

[9] Badrossaway, M.R., Ravandi, S., Morshed, M.: Fundamental Parameters Affecting Yarn-Pullout Behavior, Journal of the Textile Institute, Vol. 92(3), p. 280-287, ISSN 0040-5000, 2001.

[10] Valizadeh, M., Ravandi, S., Salimi, M., Sheikhzadeh, M.: Determination of Internal Mechanical Characteristics of Woven Fabrics Using the Force-Balance Analysis of Yarn Pullout Test, Journal of The Textile Institute, Vol. 99(1), p. 47-55, ISSN 0040-5000, 2008.

[11] Pan, N., Yoon, M.Y.: Behavior of Yarn Pull-Out from Woven Fabrics: Theoretical and Experimental, Textile Research Journal, Vol. 63(11), p. 629-637, ISSN 0040-5175, 1993.

[12] Gawandi, A., Thostenson, E.T., Gilllespie, J. W.: Tow Pullout Behavior of Polymer-Coated Kevlar Fabric, Journal of Materials Science, Vol. 46(1), p. 77-89, ISSN 00222461, 2011.

[13] Bilisik, K., Korkmaz, M.: Single and Multiple Yarn Pull-Outs on Aramid Woven Fabric Structures, Textile Research Journal, Vol. 81(8), p. 847-864, ISSN 0040-5175, 2011.

[14] Bilisik, K.: Pull-Out Properties Of Polyester Woven Fabrics: Effects Of Softening Agent And Interlacement On Single And Multiple Yarn Pull-Out Forces And Analysis By Statistical Model, Fibers and Polymers, Vol. 12(8), p. 11061118, ISSN 1229-9197, 2011.

[15] Bilisik, K.: Experimental Determination of Fabric Shear by Yarn Pull-Out Method, Textile Research Journal, Vol. 82(10), p. 1050-1064, ISSN 0040-5175, 2012.

[16] Bilisik, K.: Experimental Determination Of Yarn Pull-Out Properties Of Para-Aramid (Kevlar®) Woven Fabric, Journal of Industrial Textiles, Vol. 41(3), p. 201-221, ISSN 1528-0837, 2012.

[17] Sergienko, O.V., Bindschadler, R.A., MacAyeal, D.R.: StickSlip Behavior of Ice Streams: Modeling investigations, Annals of Glaciology, Vol. 50(52), p. 87-94, ISSN 02603055, 2009.

[18] Bilisik, K.: Stick-Slip Behavior of Para-Aramid (Twaron®) Fabric in Yarn Pull-Out, Textile Research Journal, Vol. 83(1), p. 13-33, ISSN 0040-5175, 2013.

[19] MathWorks, MATLAB R2008a-version 7, Computer program, The MathWorks Incorporation, Natick, MA, USA, 2008. 